Abstracta Iranica Abstracta Iranica

Revue bibliographique pour le domaine irano-aryen

Volume 23 | 2002

Comptes rendus des publications de 2000

Zoroastrianism in China, China Archaeology and Art Digest. IV-1, (Décembre 2000), Hong Kong - Beijing, Art Text, $507 \mathrm{p}$.

Étienne de La Vaissière

(2) OpenEdition Journals

Édition électronique

URL : http://journals.openedition.org/abstractairanica/35236

DOI : 10.4000/abstractairanica.35236

ISSN : 1961-960X

Éditeur :

CNRS (UMR 7528 Mondes iraniens et indiens), Éditions de l'IFRI

Édition imprimée

Date de publication : 15 mai 2002

ISSN : 0240-8910

Référence électronique

Étienne de La Vaissière, "Zoroastrianism in China, China Archaeology and Art Digest. IV-1,

(Décembre 2000), Hong Kong - Beijing, Art Text, 507 p. », Abstracta Iranica [En ligne], Volume 23 | 2002, document 55, mis en ligne le 08 février 2010, consulté le 25 septembre 2020. URL : http://

journals.openedition.org/abstractairanica/35236; DOI : https://doi.org/10.4000/abstractairanica. 35236

Ce document a été généré automatiquement le 25 septembre 2020

Tous droits réservés 


\title{
Zoroastrianism in China, China Archaeology and Art Digest. IV-1, (Décembre 2000), Hong Kong - Beijing, Art Text, 507 p.
}

\author{
Étienne de La Vaissière
}

La revue China Archaeology and Art Digest, essentiellement consacrée à des résumés anglais des publications archéologiques chinoises, a centré dans ce volume son dossier thématique sur la présence des Iraniens en Chine jusqu'aux Tang (pp. 7-216). Elle offre la traduction de plusieurs articles importants parus sur ce sujet ces dernières années en chinois. Lorsqu'on connaît l'importance des découvertes effectuées sur le sol de Chine dans le domaine de l'iranologie, elle se révèle être un outil indispensable pour quiconque veut travailler sur les aspects les plus orientaux du monde iranien altimédiéval, et cela par le grand nombre de renseignements nouveaux comme par le large point de vue sur l'historiographie chinoise. Le premier article, écrit par le chercheur le plus actif en ce domaine, Rong Xinjiang, consiste en une fort utile mise en perspective de cette historiographie iranologique chinoise, notamment dans ses débats les plus récents qui informent plusieurs articles du volume. Les articles suivants sont consacrés aux deux découvertes récentes de tombes d'Iraniens orientaux faites en Chine, déjà signalées dans Abs. Ir. 22. $\mathrm{n}^{\circ}$ 107-108, et notamment à l'analyse des bas reliefs qui les ornaient. Il faut noter qu'on trouvera de meilleures photos, en couleur, dans Wenwu, 2001, n ${ }^{\circ}$ 1, et que B. Marchak prépare pour les CRAI (2002) un article d'analyse iconographique sur ces tombes. D'autres découvertes, moins connues, sont ajoutées au corpus, pas toujours à bon escient (ainsi on doute que l'iconographie de la stèle de Dame Yang et que le temple «zoroastrien » de Jiexu aient vraiment rapport avec le zoroastrisme, en revanche l'ossuaire du Musée du Palais de Pékin est correctement identifié). Les articles suivant traitent d'histoire religieuse et politique : quel rôle jouaient exactement les sabao (du sanskrit sārthavāha chef de caravane par sartapao en sogdien) de l'administration chinoise? chefs de communautés ou fonctionnaires chargés uniquement des cultes? et d'autre part quelle était la place 
exacte du zoroastrisme en Chine? L'un des courants dominants de l'historiographie chinoise actuelle veut en effet assimiler avec Ahura Mazda le dieu du ciel cité par les Histoires dynastiques comme la principale divinité de Turfan, ce qui semble fort douteux. Enfin un gros article de Rong Xinjiang rassemble un grand nombre de données sur la présence sogdienne en Chine sous les Tang, données souvent tirées d'inscriptions funéraires ou de découvertes archéologiques mal accessibles en Occident. En cela cet article est tout à fait novateur. On regrettera simplement que l'identification des Sogdiens y repose toute entière sur leurs noms de famille, alors que l'utilisation des prénoms ou de critères sociologiques (intermariages, généalogies) donnerait de bien meilleurs résultats.

INDEX

Thèmes : 3.1. Est de l'Iran

\section{AUTEURS}

ÉTIENNE DE LA VAISSIÈRE

ENS - Paris 